\title{
Antigenic Analysis by 2-Dimensional Radio-Coprecipitation ${ }^{1}$
}

In a previous publication, the preparation, labelling, and utilization of ${ }^{125}$ I-labelled antibodies to human chorionic gonadotrophin (HCG) was described ${ }^{2}$. To further elucidate the mechanisms of HCG-antibody interactions, it seemed desirable to employ radio-labeled antigen. In this communication, findings on the antigenic heterogeneity of commercial HCG assessed by the use of ${ }^{125}$-I-labelled antigen will be reported. Data in the present study were evaluated by a modification and extension of the technique of radioimmunoprecipitation which was termed 2-dimensional radio-coprecipitation (2-DRCP).

Materials and methods. The antigen procurement (Antuitrin-S, Parke-Davis) and method of rabbit anti-HCG antibody production has previously been described ${ }^{2,3}$. Purified HCG $(1700 \mathrm{IU} / \mathrm{mg})$ was labeled with ${ }^{125} \mathrm{I}$ by the method of HunTer and GREen wOOD ${ }^{4}$. Pooled fractions of the radio-hormone preparation contained $1.9 \mu \mathrm{g}$ protein $/ \mathrm{ml}$ with a specific activity of $138.4 \mu \mathrm{Ci} / \mu \mathrm{g}$. ${ }^{125} \mathrm{I} \mathrm{HCG}$ was suspended in $0.05 \mathrm{M}$ phosphate buffer stabilized with $1.0 \%$ bovine serum albumin. $5 \mu \mathrm{l}$ of ${ }^{125}$ I HCG were applied to a cellulose polyacetate membrane and electrophoresed in $0.05 M$ tris-barbital-sodium barbital buffer mixed in equal proportions with formamide. A current of $2.5 \mathrm{~mA} / \mathrm{strip}$ was applied for $1 \mathrm{~h}$. After drying, the membrane strips were analyzed for radioactivity on a radiochromatogram scanner.

All phases of the 2-DRCP procedure were performed in $12 \times 75 \mathrm{~mm}$ pyrex siliconized test tubes. The first phase required $0.5 \mathrm{~cm}^{3}$ of radiohormone diluted $1: 25$ in normal saline and $0.5 \mathrm{~cm}^{3}$ of deactivated anti-HCG antiserum in dilutions extending from $1: 10$ to $1: 2500$. The extent of the dilution series was estimated from a previously obtained hemagglutination titer ${ }^{2}$. The reactants were incubated at $37^{\circ} \mathrm{C}$ for $30 \mathrm{~min}$ and overnight at $4^{\circ} \mathrm{C}$. Excess goat antiserum to rabbit $\gamma$-globulin (GARG) was then added and incubated as described for the first antiserum. Following centrifugation and washing, the sediment in the tubes was counted for radioactivity against a standard and plotted as cpm versus reactant dilution. The residues were washed with $0.1 M \mathrm{Na}_{2} \mathrm{CO}_{3}$ and total protein was determined ${ }^{5}$. In a control series, nonimmune rabbit $\gamma$-globulin was substituted for anti-HCG serum and titered against the radiohormone.

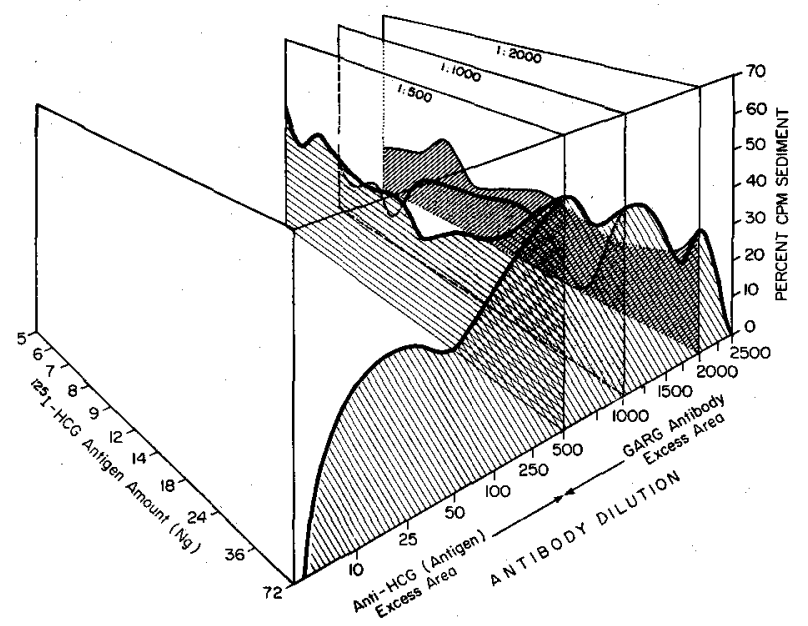

Fig. 1. A 2-dimensional planar profile of the radio-coprecipitation method is demonstrated. Initially, the antiserum was titrated on the $\mathrm{X}$-axis, then the antigen $\left({ }^{125} \mathrm{I}-\mathrm{HCG}\right)$ on the $\mathrm{Z}$-axis. All precipitation occurs in the GARG antibody excess zone.
The anti-HCG serum precipitation peaks obtained from the GARG antibody excess zone dictated the serum dilutions for use in the second half of the procedure. A second dimension was obtained for all peaks in this zone by diluting the ${ }^{125} \mathrm{I} H C G$ antigen $(1: 15$ to $1: 325)$ in normal saline and mixing this solution with constant amounts $(0.5 \mathrm{ml}$ value) of anti-HCG antiserum at the peak precipitating dilutions obtained previously. All incubations and washings followed the above procedures except that protein was not determined. However, tests of the supernatants were carried out in Preer tubes ${ }^{6}$ for the serum dilutions. Three different preparations of ${ }^{125}$ I HCG antigen (using

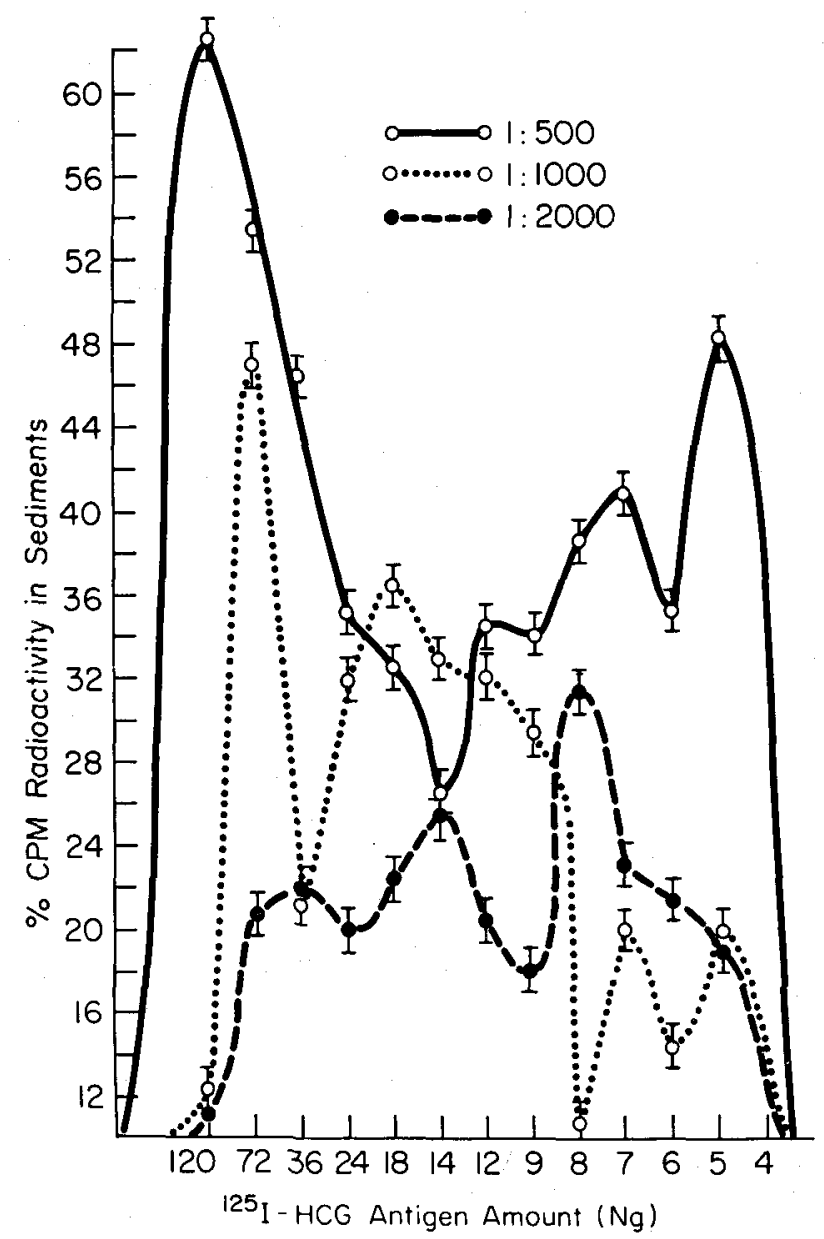

Fig. 2. Varying dilutions of ${ }^{125}$ I-HCG were titrated against constant amounts of antibody diluted 1:500,1:1000 and 1:2000. Five peaks or fractions, numbered as Roman numerals in the text, were demonstrated each with varying magnitudes at different serum concentrations. The closed vertical bars indicate the control range variation.

1. This work was supported by AEC Contract No. AT(11-1)2031 and NIH Grant No. HD-0068-12.

2 J. Quinones, G. Mizejewski and W. Beierwaltes, J. nucl. Med. 12,69 (1971).

${ }^{3}$ G. J. Mize Jewski and J. Baron, Experientia 26, 1369 (1970).

4 W. B. Hunter and G. C. Greenwood, Nature, Lond. 194, 495 (1962).

5 O. H. Lowry, N. J. Rosebrough, A. L. Farr and R. J. Randall, J. biol. Chem. 193, 265 (1951). 
duplicate samples) were subjected to 2 -DRCP evaluation employing the same batch of rabbit antiserum.

Results and discussion. ${ }^{125}$ I HCG subjected to Sepahadex G-100 column chromatography yielded 1 minor component termed fraction $\mathrm{A}$, and 2 major components, fractions $\mathrm{B}$ and $\mathrm{C}$. Fraction $\mathrm{B}$ had hemagglutination inhibition ${ }^{7}$ activity while fraction $C$ had only low grade $( \pm$ ) activity. Fraction A was not submitted to testing. The two former fractions were further elucidated by cellulose acetate electrophoresis and radioscanning. These procedures demonstrated that fraction $\mathrm{B}$ consisted of 5 subcomponents while fraction $\mathrm{C}$ appeared as a single peak. 4 of the B-subfractions migrated toward the anode and 1 toward the cathode. In summary, fraction B possessed immunological activity and multiple components while fraction $\mathrm{C}$ displayed low immunoactivity and unit identity.

The titration of anti-HCG serum which was performed first established the precipitating pattern of the GARG antibody system. This first step in the technique indicated the optimum points of precipitation along a dilution spectrum of the anti-HCG serum. The results of titrating antiHCG serum with constant amounts of ${ }^{125}$ I-HCG and GARG are illustrated in Figure 1 (X-axis). The ${ }^{125} \mathrm{I}-\mathrm{HCG}$ radioantigen is not employed as antigen excess in either the first or the second phase of 2-DRCP, and the major precipitating peaks occur in GARG antibody excess. The precipitation peaks for the GARG-anti-HCG system occurred at anti-HCG serum dilution 1:500, 1:1000, and $1: 2000$. The small peak on the left side of the diagram (antibody dilution area) precipitated in the anti-HCG serum excess zone. This was not an area of GARG antibody excess;

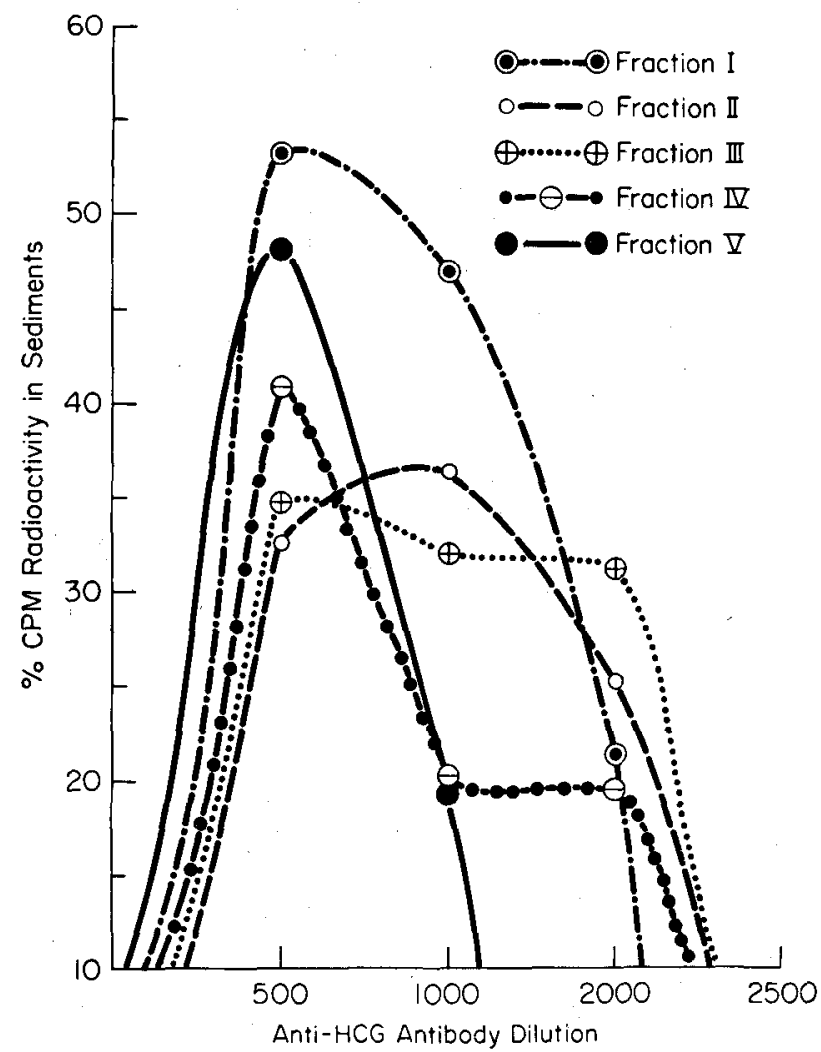

Fig. 3. Each of the peaks seen as fractions I through $V$ were plotted at the anti-HCG antibody dilutions $1: 500,1: 1000$ and $1: 2000$. The individual precipitin curves for the 5 fractions are seen together with their contribution at each serum dilution. therefore, precipitation should not have occurred and this peak may represent antigen trapping. The radioactivity counts in each of the sediments could be confirmed by comparison to the spectrometric counting results of the corresponding supernatants. The points obtained from the protein curve closely approximated the precipitin curve in the first phase of 2-DRCP. A test of the supernatants employing Preer tube precipitation failed to demonstrate the presence of anti-HCG antibody in the GARG excess zone. However, the presence of anti-HCG in the supernatant of serum dilution $1: 10$ through $1: 100$ confirmed this area as the anti-HCG antiserum (antigen) excess zone. Controls consisting of normal rabbit serum were substituted in place of anti-HCG and consistently resulted in only $1-2 \%$ $\mathrm{cpm}$ in the sediment. Omission of the second antibody (GARG) resulted in the absence of a visible precipitate and meaningless radioactivity counts.

The HCG antigen components were analyzed next in the zone of GARG antibody excess using constant amounts of anti-HCG antibody at the peak values of serum titration, namely, 1:500, 1:1000 and 1:2000 dilution. The titration was performed at ${ }^{125} \mathrm{I}-\mathrm{HCG}$ antigen dilutions $1: 15$ through $1: 350$; this was $120 \mu \mathrm{g}$ to $5 \mathrm{ng}(0.2-0.009 \mathrm{IU})$ of $\mathrm{HCG}$. This titration completed the second phase of the analysis and the entire procedure is represented by the 2-dimensional planar profile in Figure 1. Five peaks occurred in each case, but the magnitude of the peaks varied widely at different serum concentration (Figure 2). When each of the peaks represented by fraction 1 through 5 were plotted against the 3 anti-HCG serum dilutions, it could be seen that the precipitation point produced at each serum dilution was really composed of 4 to 5 components whose summation contributed to each of the peaks observed (Figure 3). Fraction 1 was the major antigen component contributing significantly at all 3 dilutions. However, fraction II was a greater constituent at serum dilution 1:1000 than either of the other 2 dilutions. Fraction III extended over the 3 peaks contributing similarly to all serum dilutions. Fraction IV was the major antigenic constituent at serum dilution 1:500, but contributed very little at the other serum dilutions. Fraction $\mathrm{V}$ contributed mainly to the peak at $1: 500$, less to $1: 1000$, and none at all to peak $1: 2000$.

The experiments above were repeated for fraction $\mathrm{C}$ which showed very little immunological activity and concommitantly, very little precipitate was formed. However, 3 antibody peaks of precipitation resulted which would have been beyond the sensitivity of the aforementioned immunological tests. Once again, a small precipitation peak occurred in the anti-HCG excess zone as with fraction $B$. Anti-HCG serum precipitation peaks occurred at $1: 250$, $1: 1250$ and $1: 1750$ dilution in the first dimension. Radioactivity counts of the supernatant again confirmed points seen on the antibody curve. At these serum dilutions, 3 peaks were detected in the second dimension which precipitated barely $14.0 \%$ of total count. The 3 points appeared at antigen dilution $1: 75,1: 200$ and $1: 350$. Thus, fraction C showed 3 antibody precipitable groups by 2-DRCP which were undetectable employing hemagglutination inhibition analysis.

Precipitation in liquid media (2-DRCP) using ${ }^{125}$ I-HCG provided a multi-phase precipitin curve of the heterogeneous antigens in the system under present investigation. This modified method of radioimmunoprecipitation differs

6 J. R. PReER JR., J. Immunol. 77, 52 (1956).

7 W. R. Butr, The Chemistry of the Gonadotropins (Charles C. Thomas, Publishers, Springfield, Ill. 1967), p. 107. 
from those previously published ${ }^{8-10}$ in two ways: 1 . antiserum in varying concentrations is first titered against constant amounts of radioantigen and antiglobulin antibody and 2. a second dimension is provided by titrating varying dilutions of the radioantigen against constant amounts of the homologous antiserum determined in the first step. The combining of steps 1 and 2 (Figure 1) at each precipitation point along the serum dilution axis results in 2-dimensional prospective, showing the multiple antigenic determinants which have contributed to anti-HCG antibody formation. The individual precipitin curve for each antigen in the system can then be constructed (Figure 3) from the second dimension.

Radio-coprecipitation (2-DRCP), as performed in double dimension, will allow the investigator to achieve optimal serum dilution analysis to detect specific antigenic constituents in the nano- and pikogram range (5 ng in the present study). The present method of 2-DRCP may be applied to screening sera for radioimmunoassays to determine points of optimal precipitation. This new technique, in turn, may relate the purity of the antigenic preparations employed in radioimmunoassays.
Zusammenfassung. Neue Variante des Radio-Immundiffusionstests mit Antigenanalyse von menschlichem Gonadotrophin.

\section{G. J. Mizejewski and Jennifer Baron}

Department of Biology, University of South Carolina, Columbia (South Carolina 29204, USA); and Department of Internal Medicine,

University of Michigan Medical Center, Ann Arbor (Michigan 48104, USA), 18 October 1971.

${ }^{8}$ M. Cohn, Methods in Medical Research (Ed. A. C. Corcoran; The Yearbook Publishers, Inc., Chicago, Ill. 1951), vol. 5, p. 501.

${ }^{9}$ I. M. RoITT and D. DoNIACH, Mechanisms in Hypersensitivity (Ed. Schaffer, G. La Grippo and M. Chase; Little, Brown and Co., Boston 1959), p. 325 .

10 G. J. GLeICH and R. R. STAN KIEVIC, Immunochemistry 6; 85 (1969).

\section{The Influence of Proteolytic Enzymes Inhibitor on the Course of Lymphocyte Transformation in vitro}

It is known that both phytohemagglutinin (PHA), streptolysin S, antilymphocyte sera, antigen and antigenantibody complexes induce lymphocytes transformation in vitro ${ }^{1-5}$. Transformation stimulators enhance oxygen consumption ${ }^{6}$, RNA synthesis ${ }^{7}$, and also cause changes in the morphological character of lymphocytes. Using histochemical methods, HirschHORN et al, ${ }^{3}$ demonstrated that in the course of the transformation the content of acid hydrolases in the stimulated lymphocytes increases. Moreover, the PHA simplifies the destructive influence of streptokinase $\mathrm{S}$ on lymphocyte lysosomes ${ }^{8}$. DIENGDOH and $\mathrm{T}_{\mathrm{CRK}}{ }^{9}$ were able to demonstrate that lymph node cells contain more acid hydrolases after antigen stimulation. Analogical changes were observed in blood leukocytes of rabbits after allogenic skin transplantation ${ }^{10}$.

The present communication is to show the role of proteolytic enzymes inhibitor in the course of lymphocyte transformation in vitro.

Material and methods. The investigations were carried out on lymphocytes obtained from the spleen or lymph nodes of immunized guinea-pigs weighing 350-450 g. Male guinea-pigs were immunized by human serum albumin (HSA) produced by Biomed, Poland. Antigen was injected with mineral oil as an adjuvant, in the proportion $1: 1$, to the whole quantity of $2 \mathrm{mg}$ HSA for 1 guinea-pig. The experiments were carried out 20 to 30 days after the immunization. Cells of the spleen and lymph nodes were prepared in suspensions containing $2-4 \times 10^{6}$ lymphocytes $/ \mathrm{ml}$. The lymphocyte cultures were incubated in tubes at $37^{\circ} \mathrm{C}$ for

1 P. C. Nowell, Cancer Res, 20, 462 (1960).

2 K. Carstairs, Lancet 2, 984 (1961).

${ }^{3}$ R. HirschHorn, K. Hirschhorn and G. Weissmann, Blood 84, 30 (1967).

4 J. Foerster, J. P. Lamelin, I. Green and B. Benacerraf, J, exp. Med. 129, 295 (1969)

${ }^{5}$ N. Bloch-Schachter, K. Hirschhorn and J. W. Uhr, Clin. exp. Immun. 3, 889 (1968).

- H.Warnatz, in Current Problems in I mmunology (Ed. O.WestPhaL; Springer-Verlag, Berlin, New York 1969), p. 131.

${ }^{7}$ H. L. Cooper and A. D. Rubin, Blood 25, 1014 (1965).

8 R. HirschHorn, G. BritTinger, K. HirschHorn and G. WeissMANN, J. Cell. Biol. 37, 412 (1968).

9 J. V. Diengdoh and J. L. TuRk, Nature, Lond. 207, $1405(1965)$.

10 H. Tchórzewski, J. Niedworok, Acta physiol. polon. 21, 393 (1970).

Influence of inhibitor of proteolytic enzymes on transformation rate, oxygen consumption and incorporation of ${ }^{14} \mathrm{C}$-glycine by lymphocytes immunized guinea-pigs in vitro

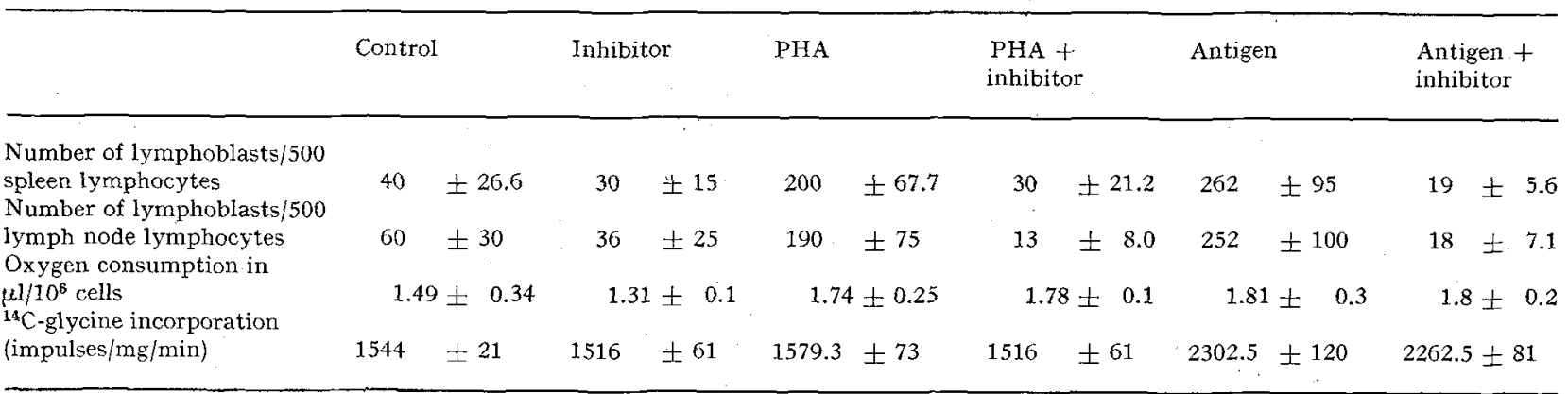

